DOI:

\title{
INTERLANGUAGE PHRASEOLOGICAL HOMONYMS ON THE DIALECTAL BACKGROUND
}

\author{
Natalia Ignatieva \\ PhD \\ The Herzen State Pedagogical University of Russia \\ (St. Petersburg, Russia) \\ e-mail: nataliagasheva@yandex.ru
}

\begin{abstract}
The article deals with the peculiarities of interlingual homonymy in phraseology in closely related languages, highlights the phenomenon of interlingual enantiosemia on the example of Russian and Czech, identifies the main causes of its occurrence. An attempt is made to illustrate the analyzed phenomenon with the help of regional dialects, which make it possible to trace the evolution of the studied lexical units in the diachronic and synchronic aspects. The material of the study allows us to conclude that the functioning in dialects of a particular meaning of the word, which is not already found in the modern literary language, indicates the possibility of folk phraseology to reconstruct the long-lost part of the language and thus make a valuable contribution to the disclosure of the history and culture of the nation.
\end{abstract}

Keywords: cross-language homonyms, interlingual enantiosemy, dialect phraseology, Russian language, Czech language

\section{МЕЖЪЯЗЫКОВЫЕ ФРАЗЕОЛОГИЧЕСКИЕ ОМОНИМЫ НА ДИАЛЕКТНОМ ФОНЕ}

\author{
Наталья Игнатьева \\ Кандидат филологических наук \\ Российский государственный педагогический университет имени А. И. Герцена \\ (Санкт-Петербург, Россия) \\ e-mail: nataliagasheva@yandex.ru
}

\begin{abstract}
Аннотация. В статье рассматриваются особенности межъязыковой омонимии во фразеологии близкородственных языков, выделяется явление межъязыковой энантиосемии на примере русского и чешского языков, указываются основные причины ее возникновения. Предпринимается попытка иллюстрации анализируемого явления с помощью региональных диалектов, дающих возможность проследить эволюцию исследуемых лексических единиц в диахроническом и в синхроническом аспектах. Материал исследования позволяет заключить, что функционирование в диалектах того или иного значения слова, не встречающегося уже в современном литературном языке, свидетельствует о возможности народной фразеологии реконструировать давно утраченную часть языка и тем самым внести ценный вклад в раскрытие истории и культуры народа.
\end{abstract}

Ключевые слова: межъязыковые омонимы, межъязыковые энантиосемы, диалектная фразеология, русский язык, чешский язык

ВВЕДЕНИЕ. Понятие межъязыковой омонимии является достаточно спорным и неоднозначным. Данное явление (в широком понимании) охватывает все то, что в рамках однопорядковых языковых уровней формально идентично, а семантически различно в контактирующих языках. Если возможность относительного формального тождества межъязыковых омонимов признается большинством ученых, то степень семантического расхождения определяется весьма по-разному (Ignat'eva 2016).

ОБЗОР ЛИТЕРАТУРЫ. Многие ученые обращали внимание на явление межъязыковой омонимии и работали над его научным осмыслением (Suprun 1958: 36-38; Budagov 1974: 141-146; Selivanov 1976: 118; Ryl'skiy 1959: 163-164 и ряд других). Р.А. Будагов выделил категорию межъязыковых омонимов в близкородственных языках и, отмечая ее специфичность, писал: «Одно дело, когда речь идет о несовпадении между неродственными языками (имеются в виду несовпадения в плане содержания - Н.И.), другое - между языками родственными, в свою очередь, в близкородственных языках создается иная ситуация, чем с родством более отдаленным» (Budagov 1974: 142). Отличие связано с тем, что большинство межъязыковых омонимов и паронимов в близкородственных языках вызвано распадом полисемии либо следствием расширения/сужения значений слов, восходящих к одному этимону. Это явление порождает межъязыковые энантиосемы, фонетически сходные, но с прямо противоположными значениями и имеющие общее происхождение (Fedorov 2013: 20).

МЕТОДЫ ИССЛЕДОВАНИЯ. МЫ рассматриваем межъязыковую энантиосемию на примере русского и чешского языков. В качестве материала используются данные «Полного словаря фразеологии народных

\footnotetext{
${ }^{1}$ Исследование выполнено при финансовой поддержке Российского научного фонда (проект №17-18-01062, реализуемый в Санкт-Петербургском государственном университете)
} 
говоров» (далее ПСФРНГ), масштабного проекта фразеологического семинара профессора В.М. Мокиенко (Mokienko, Nikitina 2018). Реализуемый в словаре принцип лексикографической полноты (Mokienko 2012) дает возможность значительно расширить охват материала: в состав словника войдут не только областные, но и общенародные фразеологизмы, что позволит представить фразеологию народных говоров на широком лингвокультурологическом фоне. Ценность и уникальность диалектного материала для нашего исследования представляется в его неиссякаемом источнике фразеологизмов, чьи компоненты сохранили свои исконные значения, тогда как в современном языке эти значения в большинстве случаев уже устарели или и вовсе были утрачены и уступили свое место новым.

Данные словаря предлагают богатый выбор примеров, однако по причине ограничения объема статьи мы сосредоточились на относительно редких, не самых часто встречающихся единицах, но при этом не менее показательных для наглядного представления рассматриваемого нами явления энантиосемии.

Методы данного исследования следующие: описательно-аналитический, сравнительно-исторический, приём сплошной выборки,. Избранные методологические основы позволяют проанализировать специфику межъязыковой энантиосемии в близкородственных языках.

Материал ПСФРНГ дает возможность проследить в народных говорах эволюцию той или иной лексемы как в диахроническом аспекте (есть примеры, датируемые XVIII, XIX веками), так и в синхроническом. И сохранение у некоторых слов в народной фразеологии их первоначальных значений еще раз подтверждает огромную роль диалектологических материалов в раскрытии истории и культуры народа.

РЕЗУЛЬТАТЫ И ДИСКУССИЯ. По утверждению К.В.Федоровой, «первопричиной семантических расхождений (в словах близкородственных славянских языков - Н.И.) явился синкретизм общеславянской основы. В ходе эволюции языка и мышления эта синкретичность, многозначность разрушалась, и значения дифференцировались. Из общей сферы понятия постепенно выделялись конкретные семантические оттенки, которые порой оказывались антонимичными друг другу» (Fedorova 2013: 72).

Современное русское бранить в значении «ругать» соответствует чешскому branit - защищать. Первоначальная семантика общеславянского borti была обобщена и совмещала значения «оборонять, охранять, воевать, сражаться» и «ругать». Со временем из этой единицы выделились древнерусские брань со значением «защита» и боронь - «нападение». В отличие от чешского языка, в русском семантика атаки, нападения победила и за лексемой бранить закрепилось значение «ругать». Существование семантики «оборонять, охранять, воевать, сражаться» в русском языке подтверждает материал словаря (ПСФРНГ), в котором мы находим иллюстрацию к этому значению, датируемую XV веком:

Соступиться на брань. Пск. (1433). Начать битву, сражение (ПОС 2: 144).

Все остальные примеры словарной статьи включают уже современные случаи употребления и содержат только значение «ругать».

Рассмотрим еще один пример расхождения значений у общеславянского корня *-trav, которому была свойственна сема «пища, продукты», что подтверждается значением древнерусского трава - «то, что употреблял в пищу скот» от травить - «потреблять даваемую пищу». Дальнейшее развитие значения до современного - «растение» связано с метонимическим переносом: «пища для скота - пища, состоявшая из разного вида растений - собственно растения» (Fedorova 2013: 74). Первичная семантика этого корня сохранилась в чешском: strava, potrava - «пища», potraviny - «продукты», trávit - «переваривать», trávení «пищеварение». Противоположная семантика реализуется в русском языке: травить, отравить, отрава - «яд, отравленная еда». Обратившись к словарю, мы находим примеры до сих пор сохранившегося в некоторых говорах значения «пища для скота»:

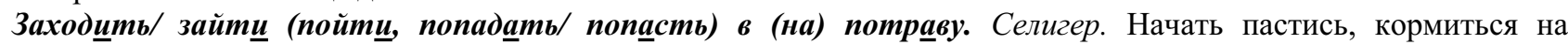
засеянном поле (о скоте) (Seliger 2013: 5, 76).

Наводить/ навестй потравуу. Пск. Портить посевы (о домашних животных) (ПОС 19: 278).

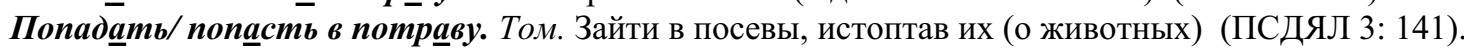

Мы видим, что в говорах присутствует нейтральная оценка. ПСФРНГ также дает примеры из говоров с уже негативной окрашенностью, но с сохранением значения компонента как «пища для скота»:

Ху, истравь тебя (его, вас и т.д.)! Алт. Бран. Недоброе пожелание, проклятье (СРГА 2-1: 194). < Истравить съесть корм, не предназначенный для скармливания в данное время.

Истравь тебя (его, вас и т.д.) в шарьц! Алт. Бран. Недоброе пожелание, проклятье (СРГА 2-1: 194).

Еще одной причиной возникновения и развития энантиосемии, как отмечает К.В. Федорова, служит различная степень интенсивности действия, заложенная в производящей основе. Иллюстрацией может послужить противопоставление лексем рушить (русск.) - «уничтожать с применением грубой силы, резко» и rušit (чешск.) - «беспокоить, мешать». Значение древнерусского рушить первоначально было «копать», а позднее появилось «уничтожать, ломать». Согласно словарю М. Фасмера (2004), производящая основа рух обозначает «суматоху, волнение, тревогу». В словаре Н.М. Шанского (1994) находим, что исходное значение рушить — «заставлять двигаться», а также указано, что рассматриваемый нами глагол того же корня, что и рвать. По предположению К.В. Федоровой, «возникновение антитезных значений <..> связано с разными ассоциациями носителей того или иного языка по поводу характера и силы воздействия на объект» (Федорова 2013: 79). Принимая во внимание вышесказанное, становится более ясным происхождение выражения рушить горьки слёзушки.

Это единственный пример, который мы находим в словаре (ПСФРНГ), употребления глагола рушить не в привычном значении «уничтожать, ломать», а «ронять, рассыпать». 
Рушить горьки слёзушки. Север. Фольк. Проливать слезы (СРНГ 35, 290). < Рушить - ронять, рассыпать что-л. Выражение употребляется в причитаниях.

Из примера видно, что глагол рушить представляет в данном говоре действие по степени интенсивности гораздо более слабое, чем в современном русском языке.

Следующей причиной энантиосемии К.В. Федорова выделяет «неисконное семантическое расхождение лексем, связанное с языковой эволюцией» (Fedorova 2013: 79). С данным процессом соотносится явление аналогии в парадигматическом плане, когда развитие нового значения в сторону полного расхождения с общеславянским частично основывалось на сосуществовании родственных новообразований с той же семантикой.

Обратимся к глаголу заказать, образованному префиксальным способом от праславянского * kazati. Если в древнерусском языке лексема заказати характеризуется двумя противоположными значениями: «приказать кому-нибудь изготовить, сделать что-нибудь» и «запретить», то на современном этапе слово сохранило только семантику приказа, наказа, утратив значение запрета. В русском языке уже в XVIII в. значение «запретить» сопровождалось пометами «выходящее из употребления», тогда как в чешском языке это значение входит в активный запас лексики до сих пор. С одной стороны, недифференцированный характер этимона здесь также стал толчком развития антонимичных значений. Кроме того, еще был задействован и словообразовательный фактор. «В случае лексем заказать (русск.) - zakázat (чешск.) в значении «запретить», а также запомнить (русск.) - zapomenout (чешск.) в значении «забыть» не последнюю роль в развитии противоположных значений сыграла древняя общеславянская поливалентная приставка «за-»» (Fedorova 2013:81).

Хотя уже в XVIII в. значение «запретить» выходило из употребления, в диалектной фразеологии, а точнее - в алтайских говорах, мы до сих пор встречаем эту семантику:

Родству заказать что. Алт. Закаяться, заречься, дать себе слово и совет близким не делать чего-л. (СРГА 2-1: 120).

С явлением энантиосемии связан процесс приобретения лексемой дополнительного эмоционально-оценочного значения. Рассмотрим пример, когда лексема получила эмоционально-оценочный компонент в результате ее семантической эволюции, а не в процессе номинации.

Представляет интерес слово позор - «бесчестье» и энантиосемичное чешское роzоr - «внимание».

Лексема восходит к той же основе, что и глагол позьръти - «посмотреть», и еще в ХІХ в. значение этого слова было «то, что выставлено на обозрение» (Krylov 2005).

Находим этому подтверждение и в ПСФРНГ, однако все примеры уже отмечены пометой устаревшее:

Выставлять/ выставить на позор кого, что. 1. Устар. Ставить на всеобщее обозрение, напоказ (СлРЯ ХVIII в.: 21, 102). 2. Разг. Обличать кого-л. (как правило - ставя в унизительное положение). (БМС 1998: 456); (ШЗФ 2001: 52).

Произвести на позор света что. Устар. Опубликовать что-л. (СлРЯ XVIII в.: 21, 102).

А также примеры с производным позорище:

Вступить (явиться) на позорище мира. Устар. Выйти в свет, начать общаться (СлРЯ ХVIII в.: 21, 103).

Вывести на позорище кого. Устар. Сделать кого-л. преметзом насмешек; осмеять (на сцене, в комедии) (СлРЯ XVIII в.: 21, 103). < Позорище - то, что представляется взору, что можно видеть.

Вывести (предложить) на позорище света что. Устар. Выставить на всеобщее обозрение (СлРЯ ХVIII в.: 21, 102).

Современное значение в русском языке «постыдное зрелище, срам» слово приобрело от обычая выставлять на позор преступников.

Пригвоздить (поставить) к позорному столбу кого. Разг. Передать кого-л. позору, заклеймить позором (БТС, 891, 1272); (Ф 2, 89); (ФМ 2002, 475).

Позорный столб-столб, к которому в средние века приковывали преступников на всеобщее обозрение. БМС 1 998, 551 (Мокиенко, Никитина, 2007).

ЗАКЛЮЧЕНИЕ.Таким образом, мы попытались рассмотреть одни из основных причин, повлиявших на появление энантиосемии в межъславянском языковом пространстве и проиллюстрировать это явление примерами из ПСФРНГ. Разбор даже такого небольшого количества выражений позволяет говорить как о фразеографической, так и о социокультурологической значимости нового словарного проекта профессора В.M. Мокиенко, который станет значительным вкладом в научные исследования и лексикографические открытия.

Народная фразеология дает возможность реконструировать язык. Ведь зачастую во фразеологизмах литературного языка то или иное значение слова уже не встречается, а в диалектах до сих функционирует и активно используется.

Материал ПСФРНГ позволяет проследить в народных говорах эволюцию той или иной лексемы как в диахроническом аспекте (есть примеры, датируемые XVIII, XIX веками), так и в синхроническом. И сохранение у некоторых слов в народной фразеологии их первоначальных значений еще раз подтверждает огромную роль диалектологических материалов в раскрытии истории и культуры народа.

\section{Сокращения:}

БМС - Бирих А.К., Мокиенко В.М., Степанова Л.И. Словарь русской фразеологии. Историко-этимологический справочник. Санкт-Петербург, 1998. 704 с.

ПОС - Псковский областной словарь с историческими данными. Вып. 1-26. / Под ред. Б.А. Ларина [и др.]. Л. (СПб.): ЛГУ (СПбГУ), 1967-2016. 
ПСДЯЛ - Полный словарь диалектной языковой личности / Под ред. Е.В. Иванцовой. Томск: Изд-во Том. ун-та, $2006-2012$. Т. 1-4.

Селигер - Материалы по русской диалектологии. Словарь / Сост. С.Н. Варина, Н.В. Богданова, З.А. Петрова. Под ред. А.С. Герда. Вып. 1 - 5. СПб.: Изд-во СПбГУ, $2003-2013$.

СлРЯ XVIII в. - Словарь русского языка XVIII века / АН СССР. Ин-т рус. яз.; Гл. ред.: Ю.С. Сорокин. Л.: Наука. Ленингр. отд-ние, 1984-1991.

СРГА - Словарь русских говоров Алтая / Под ред. И.А. Воробьевой, А.И. Ивановой. Барнаул: Изд-во АлтГУ, 1993-1998. Т. $1-4$.

ШЗФ - Шанский Н.М., Зимин В.И., Филиппов А.В. Школьный фразеологический словарь русского языка: значение и происхождение словосочетаний. 4-е изд., стереотип. М.: Дрофа, 2001. 368 с.

\section{LIST OF REFERENCES}

Budagov, R. A. (1974). False friends of the translator // Man and his language. - Moskva: Izdatel'stvo Moscovskogo Universiteta, 141-146.

Ignatieva, N. D. (2016). Modern Russian-Czech interference (lexico-phraseological aspect). Dissertaciya kandidata philologicheskych nauk: 10.02.03; Sankt-Peterburg, $168 \mathrm{~s}$.

Kry`lov, G.A. E`timologicheskij slovar` russkogo yazy`ka. - SPb.: OOO «Poligrafuslugi», 2005. — $432 \mathrm{~s}$.

Mokienko, V. M. (2012). Principles of Larin's lexicography in the three-volume Big dictionary of Proverbs, sayings and similes of the Russian language // Voprosy leksikografii, 1, $70-84$.

Mokienko, V.M., Nikitina T.G. Bol`shoj slovar` russkix pogovorok. - M: Olma Media Grupp. 2007, 785 s.

Rylsky, M. F. (1956). Art of translation: articles. Performances. Notes. Kyev: Rad. Pismennik, 344 s.

Selivanov, G. F. (1976). Language contacts and the problem of interlanguage homonymy (heteronymy) // Voprosy russkogo i slavjanskogo jazykoznaniya: mezhvuzovskiy sbornik. Ivanovo: Ivanovo state University, 116-126.

Suprun, A. E. (1958). Answer to the question: what are the types of lexical homonyms in the system of Slavic languages (common to all Slavic languages, individual) // Sbornik otvetov na voprosy po jazykoznaniyu: k IV mezhdunarodnomu congressu slavistov, Moskva, 35.

Fasmer M. (2004) E`timologicheskij slovar` russkogo yazy`ka: V 4-x t.: Per. s nem. = Russisches etymologisches Wörterbuch / Perevod i dopolneniya O. N. Trubachyova. - 4-e izd., stereotip. Moskva, Astrel’ - AST, 2004, T. 4., 860 s.

Fedorova, K. V. (2013). Inter-Slavic interference in connotative and translation aspects. Dissertaciya kandidata philologicheskych nauk: 10.02.01, 10.02.30; Kazan, 170.

Shanskij, N. M. E`timologicheskij slovar` russkogo yazy`ka / N. M. Shanskij, T. A. Bobrova. - M. : Prozerpina : Shkola, $1994 .-400$ s. Mokienko, V. M., Nikitina T. G. (2018). On the concept of a complete dictionary of folk phraseology: problems of macroconstruction./ Voprosy leksikografii (Tomsk) 4, 80-106.

\section{For citation:}

Ignatieva, N. (2019) INTERLANGUAGE PHRASEOLOGICAL HOMONYMS ON THE DIALECTAL BACKGROUND. International Scientific-Pedagogical Organization of Philologists " WEST-EAST" (ISPOP). Scientific Journal WEST-EAST. Vol 1/1 N1 (October, 2019). pp. 38-41. doi:

\section{Для цитирования:}

Игнатьева, Н. (2019) МЕЖЪЯЗЫКОВЫЕ ФРАЗЕОЛОГИЧЕСКИЕ ОМОНИМЫ НА ДИАЛЕКТНОМ ФОНЕ // International Scientific-Pedagogical Organization of Philologists “WEST-EAST ” (ISPOP) . Scientific Journal WEST-EAST. Vol 1/1 N1 (October, 2019). C. 38-41. doi:

Information about the author: Natalia Ignatieva - Ph.D., The Herzen State Pedagogical University of Russia, St. Petersburg, Russia

e-mail: nataliagasheva@yandex.ru

Сведения об авторе: Наталья Игнатьева - к. филол.н., старший преподаватель, Российский государственный педагогический университет имени А. И. Герцена, Санкт-Петербург, Россия

e-mail: nataliagasheva@yandex.ru 